\title{
AS CURVAS DO TEMPO COM CAMINHOS OBLÍQUOS. APRESENTAÇÃO
}

\author{
THE CURVES OF TIME WITH OBLIQUE PATHS. PRESENTATION \\ LES COURBES DU TEMPS AUX CHEMINS OBLIQUES. PRÉSENTATION \\ LAS CURVAS DEL TIEMPO CON CAMINOS OBLICOS. PRESENTACIÓN
}

Paula Guerra

Universidade do Porto, Faculdade de Letras e Instituto de Sociologia, CITCEM, CEGOT, Dinâmia'CET, Griffith Centre for Cultural Research, Porto, Portugal

\section{Lígia Dabul}

Universidade Federal Fluminense, Programa de Pós-Graduação em Estudos Contemporâneos das Artes da e do Programa de Pós-Graduação em Sociologia, Rio de Janeiro, Brasil

É com muito gáudio que apresentamos este Volume 3 Número 1 da nossa revista sob o mote das passagens, dos tempos, das resistências e dos quotidianos. E a vida e as artes são uma miríade de relacionamentos e de relatos que se perpetuam nos tempos e nos espaços. É dentro destes que as situações mundanas acontecem e se transformam em vivências, experiências, intenções e memórias. Neste Volume, são dadas a conhecer construções imaginárias que se circunscrevem a um tempo-ação do devir. Constitutivos da vida social, os ímpetos criativos redefinem sem roteiros, em sempre novas configurações, o que se atribui a tradições e amálgamas do passado (Ingold et al., 2018). Por outro lado, todos os atos e ações são, na sua essência, fragmentos temporais que podem ser entendidos como uma espécie de conceção fenomenológica da vida e que são, na verdade, essenciais para nós - enquanto cientistas sociais - compreendermos o mundo da vida (Mourão, 2016). Tal como Schutz (1979) nos refere, estamos, de forma sistemática, a dar significados simbólicos aos lugares da realidade: através da música, da fotografia, de peças de vestuário, do desenho, da pintura. Interessante é constatar que o mote de Schutz está ubíquo neste Volume demonstrando que as relações entre as experiências vividas e as ações que levam à realização das mesmas se desenvolvem em curvas por caminhos oblíquos.

E essa obliquidade é particularmente fértil para a interpretação e compreensão dos campos artísticos que como todos os campos, são um espaço de lutas: quer dizer, lutas que visam conservar a doxa dominante ou transformar toda a estrutura do campo em causa. E apesar de Bourdieu constatar que o grau de autonomia varia consideravelmente de campo para campo, estas lutas dentro dos campos dependem também de fatores externos, seja, por exemplo, o surgimento de novos enjeux ou de novos públicos. Dentro do campo artístico, especialmente a partir do final do século XIX, fruto de uma progressiva autonomia face aos poderes exteriores (sobretudo económico e político), ocorre uma divisão entre a arte pela arte, a arte pura (onde há uma denegação da função em detrimento da forma), uma arte restrita e a arte burguesa, comercial, uma arte de grande produção (ou critério autónomo vs heterónomo) (Bourdieu, 2010). É neste jogo de interesses e de desinteresses que rolam os tempos. A própria valorização de uma atitude de desinteresse corresponde à ideologia mítica do criador, de alguém que subvaloriza as regras, métodos e técnicas, que depende apenas dos seus rasgos de génio. Existe uma espécie de interesse pelo desinteresse, já que o demonstrar demasiado interesse, demasiado esforço é apanágio dos mais desprovidos de capital artístico. Para os criadores, os dominantes no campo, tudo o que 
precisam fazer para os seus comportamentos serem distintivos é serem eles mesmos, já que os seus habitus e as suas disposições estão em perfeita sincronia com as expetativas do mundo social, que faz com que as suas ações pareçam naturais, evidentes e desinteressadas e, por conseguinte, duplamente valorizadas. Portanto, os atos de criação e de (re)criação não podem ser analisados como uma espécie de ligação ao divino, uma aura que perpassa o criador, mas, isso sim, como uma homologia entre a posição que este ocupa no campo artístico (posição de dominação ou subordinação cujo resultado são caminhos oblíquos, mas determinados (Guerra, 2019).

Partindo desta ideia, apresentamos um diálogo marcante entre Carles Feixa e José Machado Pais, intitulado "Perseguindo os ventos do tempo": Jovens, passados compostos e futuros possíveis. Trata-se da abordagem à vida e obra de um dos sociólogos mais proeminentes de Portugal e uma referência europeia e da América Latina dos estudos das artes e das juventudes. Com efeito, José Machado Pais desvela-nos o seu mundo da vida, conta-nos como foi a experiência de crescer num meio rural; mas também nos dá a conhecer as curvas da sua vida, desde o seu interesse pela música e a materialização do mesmo na adolescência com a criação de uma banda roqueira, os song's Boys, até à sua consolidação enquanto juvenólogo. Tal como Pais nos refere, aquilo que nos interessa é percecionar os emaranhados da vida e, neste caso, as suas linhas oblíquas. Como justamente refere José Machado Pais “Na linha de pensamento do arquiteto brasileiro Oscar Niemeyer, diria que não é o ângulo reto que me atrai, nem a linha reta, dura, inflexível; o que me atrai é curva livre e sensitiva. Por isso (...), prezo as curvas do tempo. É nessas curvas que surgem os encontros mais inesperados. As experiências de vida mais marcantes e potencialmente mais reflexivas emergem dos rodopios de vida, das curvas da letra $S$, a que metaforicamente se referia o repentista brasileiro que referi anteriormente. Nas curvas do tempo, eu tive a felicidade de te encontrar pelo caminho".

José Soares Neves, de seguida, leva-nos para os tempos das memórias e inflexões nos tempos do agora com o seu artigo Os estudos dos públicos nos museus nacionais: enquadramento $e$ metodologia, em que nos oferece uma visão sobre o Estudo de Públicos de Museus Nacionais (EPMN), estudo esse pioneiro no contexto português. Assim, dá-nos uma visão sobre os quadros de possibilidades teóricos e metodológicos encontrados no EPMN, tendo como mote a compreensão dos públicos e a relação destes com os museus. Temática cara às ciências sociais, os públicos de instituições artísticas e culturais ao serem desvelados nos levam não apenas a aspeto complexo da vida social, mas a fluxo que historicamente se estabelece e transforma da procura e contato das pessoas com experiências, objetos e ideias que lhes são apresentadas como relevantes ou excecionais.

Alix Sarrouy presenteia-nos com um artigo assente num estudo etnográfico realizado em torno do El Sistema. Remetendo novamente às obliquidades dos tempos-espaços, Sarrouy analisa um programa venezuelano de ensino de música sinfónica, no sentido em que pretende dar a conhecer as relações entre alunos e professores. Alix Sarouy baseia-se no conceito de attachement de Antoine Hennion, mas também nas noções de familiaridade reconfortante e de défamiliarisation, demonstrando que os tempos e as trajetórias - como nos refere José Machado Pais - são interdependentes. É uma justa homenagem a Hennion na medida em que se trata de um artigo que tendo por base uma perspetiva crítica em relação às origens e funções do significado musical, recentra o debate na interação entre os textos musicais e os atores sociais. Com efeito, Antoine Hennion na medida em que defende que o ato de interpretação musical e o significado da música 
são inseparáveis do consumo de textos pelos públicos; trata-se, então, de um processo subjetivo, onde os públicos surgem como agentes reflexivos e criativos (Guerra et al., 2019).

Patrícia Reinheimer oferece uma análise focada nas produções têxteis de Olly Reinheimer: Olly Reinheimer e a arte têxtil brasileira no pós Segunda Guerra: continuidades e descontinuidades na apropriação do "outro". O passado é a referência para este artigo, uma vez que as obras foram desenvolvidas entre as décadas de 1950 e 1970. Trata-se de texto determinante dos próprios contornos do tempo da investigadora e da sociedade brasileira que nos permitem entender as culturas materiais como ideologia e como forma de dizer, no sentido em que se assumem como redes de pertença nacionais, individuais e coletivas, fulcrais e vitais dentro no seio de uma sociedade.

Renata Oliveira Caetano com o seu artigo A presença do desenho em cartas de artistas: algumas possibilidades críticas transporta-nos a diversos períodos históricos, evidenciando padrões que se repetem nos grafismos. A par disso, a autora possibilita ao leitor a visualização de alguns exemplares de maravilhosas cartas da Coleção Fritz Lugt. Este artigo é uma reflexão tangível do ponto de vista dos atravessamentos que a história da arte tem vindo a sentir e da comunicação, visto que outrora as cartas eram o principal meio de comunicação, também entre artistas. Abarca com isso aspeto crucial da arte, que como fenômeno social abarca os diferentes modos de interação experimentados por artistas, cuja prática criativa inclui os mais diferentes contatos, conversas, formas de comunicação para além do que o produto artístico "acabado" e legitimado pode registrar (Dabul, 2016).

Guilherme Marcondes situa o seu objeto de análise no Museu de Arte Contemporânea do Ceará em Fortaleza, concretamente no Festival Solar que incluiu a exposição Terra em Transe de curadoria de Diógenes Moura. Focando-se nas artes dentro do campo nordestino, o autor destaca a exposição Terra em Transe, utilizando-a como o mote para a discussão e reflexão sobre as dimensões inerentes às questões raciais no Brasil. O seu grande foco passa por compreender os lugares de fala e, mais ainda, perceber as origens de um racismo estrutural instaurado na sociedade brasileira. Como refere o autor: "O agenciamento dos olhares e as trocas simbólicas e práticas entre fotografados/filmados e seus fotógrafos/artistas não é palpável".

Lídia Pinheiro oferece uma perspetiva da cidade de Vila Nova de Gaia com o seu artigo Conhecer a Nova Gaia - 4400. O hip-hop e a consolidação das cenas culturais juvenis em Portugal, enquanto palco das culturas juvenis, partindo da cultura hip-hop. A estética, a sonoridade e as posturas dos artistas são vistas como armas políticas e pedagógicas que se revêm na exigência de melhores condições de vida. Partindo deste pressuposto do hip-hop e das subculturas juvenis, a autora desenvolve uma abordagem em torno dos movimentos culturais, mas também enfatiza os processos de (re)construção identitária de jovens associados ao rap. Tendo em atenção o objetivo de perceber a forma como o hip-hop está presente no quotidiano dos jovens rappers, Lídia Pinheiro assevera que este movimento é crucial para a construção identitária de cada um. Está presente desde cedo nas suas vidas e é considerado como um refúgio e libertador de pensamentos e angústias presentes no dia-a-dia.

Gabriela Massote Lima apresenta o seu artigo Ninguém nasce viril, torna-se viril. Novas representações do corpo masculino na arte contemporânea. Trata-se de um levantamento 
histórico de imagens da história da arte, do cinema e cultura de massa que nos transporta à construção social da virilidade e concomitantemente a uma tentativa de naturalização dos géneros. Curvaturas assumidas pelo tempo levaram, aqui também, a que hoje a narrativa da dominação masculina não se imponha mais como algo indiscutível nomeadamente pela ação crítica do movimento feminista que conseguiu romper o círculo do reforço generalizado e da repetição de estereótipos nas mais diversas áreas. A propagação das novas imagens na nudez masculina funciona como recurso poético com potencialidades para reconfigurar padrões, propor novos regimes de identidade.

Mantendo a lógica dos processos de construção identitários, a moda desempenha um papel essencial neste campo. É a partir dessa premissa que introduzimos o registo de pesquisa de Henrique Grimaldi Figueredo: A indústria da moda e o mercado de arte contemporânea: um debate introdutório acompanhado por uma excelente entrevista ao artista, pintor, escultor e performer francês - Olivier de Sagazan. O autor traça e postula considerações chave sobre as relações existentes entre moda e arte, bem como sublinha os modos como extravasam para o campo do colecionismo corporativo das indústrias de luxo. Assim, perspetivando todas as dicotomias e paradoxos existentes, questiona as influências sobre a arte e a sua consagração nas sociedades contemporâneas. Olivier de Sagazan expressa isso mesmo na sua conversa: "Você não deve fazer da coisa artística um elemento à parte da sua vida. Seu trabalho artístico deve ser realizado com sentimentos internos muito fortes. Nós nunca estamos tão vivos como quando estamos diante de um quadro ou sobre um palco".

Por fim, Laura Lopéz Casado surge com uma resenha em castelhano do livro A New History of the Iberian Feminisms. Neste livro vemos uma trajetória do feminismo desde a década de 1970 até aos dias atuais no contexto da Península Ibérica. O livro está organizado por décadas e o seu principal objetivo é o de comprovar que todos os territórios que compõem a Península Ibérica, constituem uma rede, podendo ser entendidos como um todo. As mulheres, nesta resenha, encontram-se presentes e representadas nos tempos e nos espaços, sendo os mesmos elementos essenciais em etapas e marcos históricos. A Península Ibérica engloba uma história dinâmica e repleta de feminismos que tiveram de enfrentar uma tradição arreigada e uma Igreja Católica dominante. Silvia Bermúdez e Roberta Johnson revelam as lutas das mulheres que vivem em várias partes da Península Ibérica para alcançar uma cidadania plena.

Porto e Rio de Janeiro, abril de 2020.

\section{REFERÊNCIAS BIBLIOGRÁFICAS}

Bourdieu, Pierre (2010). A distinção. Uma crítica social da faculdade do juízo. Lisboa: Edições 70.

Dabul, Lígia (2016). Correspondência e poesia: apontamentos sobre criação, interação e disseminação da arte. Revista Maracanan, 2(14), pp. 97-106.

Guerra, Paula (2019). Nothing is forever: Um ensaio sobre as artes urbanas de Miguel Januário \pm MaisMenos \pm . Horizontes Antropológicos, 25(55), pp. 19-49.

Guerra, Paula; Sarrouy, Alix \& Brandão, Marcílio Dantas (2019). Antoine Hennion: música, mediação e amadores. Estudos de Sociologia, Recife, 2019, Vol. 2 n. 25, pp. 29-49.

Ingold, Tim; Hallam, Elizabeth \& Renheimer, Patricia (2018). Criatividade e improvisação cultural dez anos depois: uma atualização. Todas as Artes. Revista Luso-brasileira de Artes e Cultura, 1(2), pp. 135-141.

Mourão, Victor Luiz Alves (2016). Temporalização do espaço social: apontamentos para uma sociologia do tempo. Ciências Sociais Unisinos, 52 (1), pp. 69-79. 
Schutz, Alfred. (1979). Fenomenologia e relações sociais. Rio de Janeiro: Zahar.

Paula Guerra. Doutora em Sociologia. Professora de Sociologia da Faculdade de Letras e Investigadora do Instituto de Sociologia da Universidade do Porto. Professora Adjunta no Griffith Center for Social and Cultural Studies na Austrália. Investigadora colaboradora no Centro de Investigação Transdisciplinar «Cultura, Espaço e Memória», no Centro de Estudos de Geografia e Ordenamento do Território e no DINÂMIA'CET-IUL - Centre for Socioeconomic Change and Territorial Studies, Portugal. Faculdade de Letras da Universidade do Porto, Via Panorâmica, s/n, 4150-564 Porto, Portugal. E-mail: pguerra@letras.up.pt. ORCID: 0000-0003-2377-8045.

Lígia Dabul. Doutora em Sociologia. Professora de Sociologia da Faculdade de Letras e Investigadora do Instituto de Sociologia da Universidade do Porto. Professora Adjunta no Griffith Center for Social and Cultural Studies na Austrália. Investigadora colaboradora no Centro de Investigação Transdisciplinar «Cultura, Espaço e Memória», no Centro de Estudos de Geografia e Ordenamento do Território e no DINÂMIA'CET-IUL - Centre for Socioeconomic Change and Territorial Studies, Portugal. Faculdade de Letras da Universidade do Porto, Via Panorâmica, s/n, 4150-564 Porto, Portugal. E-mail: pguerra@letras.up.pt. ORCID: 0000-0003-2377-8045.

Citação:

Guerra, Paula \& Dabul, Lígia (2020). As curvas do tempo com caminhos oblíquos. Apresentação. Todas as Artes. Revista Luso-brasileira de Artes e Cultura, 3(1), pp. 4-8. ISSN 2184-3805. DOI: 10.21747/21843805/ta3n1ap 